\title{
Bionomics and Behavior/Bionomia e Compontamento Biologia de Cladomorphus phyllinus Gray (Phasmatodea: Phasmatidae) em folhas de goiabeira (Psidium guajava)
}

\author{
Clarice Diniz Alvarenga ${ }^{\bowtie}$, Hugo Ribeiro Souza, Teresinha Augusta Giustolin, \\ Carlos Augusto Rodrigues Matrangolo \& Joseilton Faria Silva
}

Universidade Estadual de Montes Claros (UNIMONTES).

\section{EntomoBrasilis 11 (2): 65-69 (2018)}

Resumo: A biologia de Cladomorphus phyllinus Gray foi estudada em laboratório, quando estes insetos foram alimentados com folhas de goiabeira (Psidium guajava L.). Espécimes de C. phyllinus, recém eclodidos e alimentados com folhas de goiabeira foram mantidos em gaiolas adaptadas de garrafas pet de $2 \mathrm{~L}$, as quais foram trocadas à medida que as dimensões do corpo destes insetos aumentavam. Foram avaliados o período de incubação, o número e a duração dos ínstares ninfais de machos e fêmeas, a longevidade dos adultos, o período de pré-oviposição e de oviposição, o número de ovos por fêmeas e a viabilidade destes. O período de incubação foi de 115,45 dias, a duração média do período ninfal dos machos foi de 102,62 e 117,67 dias, para os insetos com cinco e seis instares, respectivamente. Para as fêmeas o período ninfal médio foi de 163,27 e 179,25 dias, para os insetos com oito e nove instares, respectivamente. Os períodos de pré-oviposição e oviposição foram de 29,44 e 164,4 dias, respectivamente. Cada fêmea colocou, em média, 392,33 ovos, com viabilidade média de $22,26 \%$. As fêmeas possuem uma longevidade maior do que a dos machos, podendo viver até oito meses de idade, enquanto, os machos vivem no máximo cinco meses de idade. Essa espécie possui baixa capacidade reprodutiva, principalmente devido ao longo período embrionário e a baixa viabilidade dos ovos.

Palavras-Chave: Bicho-pau; Ciclo biológico; Cladomorphinae; Período de incubação.

\section{Biology of Cladomorphus phyllinus Gray (Phasmatodea: Phasmatidae) reared on guava tree leaves (Psidium guajava)}

\begin{abstract}
The biology of Cladomorphus phyllinus Gray was studied in laboratory, when these insects were fed with guava tree leaves (Psidium guajava L.). Newly hatched specimens of $C$. phyllinus and fed guava tree leaves were kept in cages adapted from $2 \mathrm{~L}$ pet bottles, which were changed as the body dimensions of these insects increased. The incubation period, number and duration of nymph instars of males and females, adult longevity, pre-oviposition and oviposition period, number of eggs per females and viability were evaluated. The incubation period was 115.45 days, the mean duration of the nymph males period was 102.62 and 117.67 days for insects with five and six instars, respectively. For females the mean nymph period was 163.27 and 179.25 days for insects with eight and nine instars, respectively. The pre-oviposition and oviposition periods were 29.44 and 164.4 days, respectively. Each female placed, on average, 392.33 eggs, with average viability of $22.26 \%$. Females have a longer longevity than males, and can live up to eight months of age, while males live at most five months of age. This species has low reproductive capacity, mainly due to the long embryonic period and the low viability of the eggs.
\end{abstract}

Keywords: Biological Cycle; Cladomorphinae; Incubation Period; Stick Insect.

(0) insetos da ordem Phasmatodea se destacam pela grande semelhança morfológica do corpo com gravetos, galhos, folhas e mesmo liquens. Os famídeos se encontram distribuídos por todo o planeta, exceto nas regiões polares, se concentrando especialmente nas regiões tropicais e subtropicais (Aliaga 2015). Das mais de 2.500 espécies já registradas (Whiting et al. 2003; TripLehorn \& JohnSON 2005), cerca de 800 vivem na região Neotropical (BuzZi \& MiYAZAKI 1993). No Brasil existem mais de 200 espécies descritas (Zoмpro \& Domenico 2005). Esses insetos são conhecidos como bichospau, mas existem várias outras denominações: treme-treme, taquarinha, taquara-seca, bicho-folha, bicho-palha, cipó-seco, chico-magro, mané-magro, Manuel-magro, Maria-seca (Buzzi 1994; LenKo \& PAPAVERO 1996). Os quatro últimos nomes, porém, referem-se mais a insetos da família Proscopiidae (Orthoptera: Acridoidea), que também imitam galhos secos.

A ordem Phasmatodea contém 13 famílias, que são fitófagas e alimentam-se de folhas e brotos, sendo algumas monófagas e outras polífagas (BEDFORD 1978). Algumas das espécies consideradas monófagas são Bacteria granullicolis (Blanchard) e Necrosia sparaxes Westwood (ZAPATA \& Torres 1970) e como polífagas são Heteronemia mexicana Gray, Didymuria violascens (Leach) e Podacanthus wilkinsoni Macleay

\section{Edited by:}

William Costa Rodrigues

\section{Article History:}

Received: 26.i.2018

Accepted: $10 . v .2018$
Corresponding author:

Clarice Diniz Alvarenga

3 clarice.corsato@unimontes.br

(3) http://orcid.org/0000-0002-7818-1062
Funding agencies:

$\checkmark$ Without funding declared 
(CAMousseight 2003). Algumas espécies, embora sejam polífagas, têm preferência por algumas espécies ou famílias de plantas, como é o caso de Phibalosoma phyllinum (Gray) (sinonímia de Cladomorphus phyllinus Gray) por folhas de Myrtaceae (SotToriva et al. 2008).

Os fasmatódeos são pouco prolíferos, colocando seus ovos, geralmente no chão, agrupados ou isolados. Esses ovos são operculados e apresentam vários formatos. O crescimento do corpo destes insetos é considerável, sendo esse o motivo as quais, as formas jovens, após a eclosão, apresentarem um porte incompatível com a capacidade do ovo do qual saíram, pouco tempo depois (Costa Lima 1938). Esses insetos apresentam reprodução sexuada, sendo o macho, geralmente, menor que a fêmea. Entretanto, existem espécies partenogenéticas, onde os machos são muito raros (SANTOS 1982).

Pouco se conhece sobre os Phasmatodea, pois é uma das ordens de insetos menos estudadas no Brasil (Chiquetto-Machado \& Albertoni 2017). Das reduzidas informações publicadas a maioria trata de descrições de espécies (Costa Lima 1938; Toledo Piza 1944; Zompro \& Domenico 2005) e pouco sobre aspectos de biologia e ecologia (Zapata \& Torres 1970; Dorval et al. 2003; Sotтoriva et al. 2008). Recentemente alguns trabalhos foram realizados, mas somente estudos taxonômicos incluindo algumas espécies brasileiras (HENNEMANn et al. 2016; KumagaI \& FonseCa 2009; Heleodoro et al. 2017).

Cladomorphus phyllinus Gray (Phasmatidae: Cladomorphinae) é nativo do Brasil, suas fêmeas são ápteras e podem atingir até $23 \mathrm{~cm}$ de comprimento, enquanto os machos são alados e podem atingir até $13 \mathrm{~cm}$. Esta espécie é muito próxima de Cladomorphus trimariensis Kumagai \& Fonseca, espécie recentemente descrita à partir de um holótipo coletado em Minas Gerais, completando desta forma cinco espécies deste gênero citadas no Brasil (KuMAGAI \& FonseCA 2009). C. phyllinus apresenta as sinonímias Bacteria tubeculata (Piza Jr.), P. phyllinum, Phibalosoma paulense Toledo Piza, Phibalosoma rochai Toledo Piza, Cladomorphus phillinus (Passerin d'Entreves) e Cladomorphus phyllium Vanschuytbroeck \& Cools (Zompro \& Domenico 2005; Bisby et al. 2008; BROCK et al. 2018).

Esses insetos podem provocar grandes danos em áreas de eucalipto e outros cultivos em alguns países, tais como Austrália, China, Índia, Filipinas e Estados Unidos (BAKer 2015), mas no Brasil ainda não foi relatado bichos-pau danificando espécies florestais e nem frutíferas (BuZzi \& MiYAZAKI 1993). Devido ao baixo potencial reprodutivo, os fasmídeos não são considerados pragas, sendo observados alguns poucos indivíduos em áreas cultivadas, e maior número em florestas (Costa Lima 1938). Mesmo com o crescente cultivo de espécies florestais exóticas no Brasil, como o eucalipto, as pesquisas sobre este inseto ainda são escassas. Com isso, o objetivo deste trabalho foi estudar a biologia do bicho-pau C. phyllinus, criado em folhas de goiabeira, espécie frutífera da mesma família do eucalipto.

\section{MATERIAL E METÓDOS}

Este trabalho foi desenvolvido sob condições controladas de laboratório, utilizando-se ninfas recém-eclodidas de C. phyllinus obtidas da criação mantida no Laboratório de Entomologia da Universidade Estadual de Montes Claros. Para isso, as ninfas foram individualizadas em gaiolas adaptadas a partir de garrafas pet (10 cm de diâmetro x $15 \mathrm{~cm}$ altura), fechadas na parte superior com tecido tipo "voil". Foram fornecidos água, por meio de um recipiente contendo algodão embebido e folhas das brotações de goiabeira. As folhas de goiabeira, mantidas em recipientes contendo água para melhor conservação, foram trocadas a cada três dias. Quando as ninfas atingiram o $4^{\circ}$ instar, foram transferidas para gaiolas maiores (10 cm de diâmetro x $22 \mathrm{~cm}$ de altura), também adaptadas de garrafas pet, onde permaneceram até a fase adulta. Diariamente esses insetos foram observados, visando detectar a troca de tegumento e a mudança de instar, por meio da contagem das exúvias.

Quando esses insetos atingiram a fase adulta, foram separados em casais e mantidos em gaiolas adaptadas de garrafa pet (20 $\mathrm{cm}$ de diâmetro x $40 \mathrm{~cm}$ de altura) e alimentados com folhas de goiabeira. As gaiolas foram vedadas na parte superior com tecido tipo "voil" e na base com papelão.

Diariamente, em dois horários distintos, pela manhã e ao final da tarde, os ovos obtidos dos casais foram retirados das gaiolas e transferidos para recipientes vedados com tecido tipo "voil" e identificados com o número do casal, data e horário da coleta. Os recipientes contendo os ovos foram mantidos em laboratório a $27^{\circ} \pm 1^{\circ} \mathrm{C}, 50 \pm 10 \%$ de umidade e fotofase de $12 \mathrm{~h}$, até a eclosão da ninfa.

A determinação do número e duração de cada instar foi realizada a partir de 50 ninfas recém-emergidas. Para a avaliação dos outros aspectos biológicos de $C$. phyllinus foram utilizados nove casais emergidos a partir do estudo da fase ninfal. Foram avaliados os períodos de pré-oviposição (dias entre a emergência da fêmea e a primeira postura), oviposição (dias entre a primeira e a última postura) e incubação (dias entre a postura e a eclosão da ninfa), a longevidade (dias entre a emergência do adulto e a morte deste) e o número de posturas, ovos/postura e ovos/ fêmea.

\section{RESULTADOS E DISCUSSÃO}

Ninfas machos de C. phyllinus alimentadas com folhas de goiabeira completaram o ciclo, atingindo a fase adulta após passarem por cinco ou seis instares, já as ninfas fêmeas completaram o ciclo com oito ou nove instares (Tabela 1).

Tabela 1. Número e duração média (dias) de instares de Cladomorphus phyllinus, alimentados com folhas de goiabeira. Temperatura de $27 \pm 1^{\circ}$ C; UR de $50 \pm 10 \%$ e fotofase de 12 horas.

\begin{tabular}{ccccc}
\hline \multirow{2}{*}{ Instar } & \multicolumn{2}{c}{ Machos } & \multicolumn{2}{c}{ Fêmeas } \\
\cline { 2 - 5 } & Duração do instar & \multicolumn{2}{c}{ Duração do instar } \\
\hline 1 & $22,3 \pm 7,5$ & $21,7 \pm 5,2$ & $23,5 \pm 8,7$ & $30,0 \pm 5,7$ \\
2 & $17,1 \pm 3,5$ & $18,7 \pm 5,7$ & $16,6 \pm 2,7$ & $22,5 \pm 4,3$ \\
3 & $18,8 \pm 6,6$ & $16,5 \pm 4,4$ & $21,8 \pm 4,0$ & $18,5 \pm 2,7$ \\
4 & $22,1 \pm 3,9$ & $21,8 \pm 3,8$ & $21,5 \pm 3,9$ & $19,8 \pm 0,8$ \\
5 & $22,4 \pm 5,1$ & $22,3 \pm 5,1$ & $20,6 \pm 4,5$ & $19,0 \pm 1,6$ \\
\hline 6 & - & $16,7 \pm 5,0$ & $20,7 \pm 5,6$ & $17,8 \pm 3,5$ \\
\hline 7 & - & - & $19,4 \pm 5,8$ & $18,3 \pm 6,1$ \\
\hline 8 & - & - & $19,3 \pm 5,8$ & $16,5 \pm 6,3$ \\
\hline 9 & - & - & - & $17,0 \pm 2,4$ \\
\hline Total & $\mathbf{1 0 2 , 6} \pm \mathbf{8 , 6}$ & $\mathbf{1 1 7 , 7} \pm \mathbf{8 , 6}$ & $\mathbf{1 6 3 , 3} \pm \mathbf{2 1 , 5}$ & $\mathbf{1 7 9 , 3} \pm \mathbf{1 6 , 3}$ \\
\hline
\end{tabular}

A variação na quantidade de instares entre os sexos nas espécies de fasmatódeos parece ser bastante comum, pois ZAPATA \& TORRES (1970) constataram para B. granullicolis a ocorrência de quatro e seis instares, para machos e fêmeas, respectivamente. CAMPBELl (1966) verificaram que machos e fêmeas de $P$. wilkinsoni possuem sete e oito instares, respectivamente. Dorval et al. (2003) obtiveram para B. tuberculata (sinonímia de $C$. phyllinus), alimentados com folhas de angico, oito e nove instares para fêmeas e seis e sete instares para machos. CAmousseight (2003) encontrou para a espécie $H$. mexicana sete 
instares para os machos e sete e oito para as fêmeas, quando se forneceu Eucalyptus globulus Labill. como alimento. Essa variação no número de instares, dentro de uma mesma espécie, pode estar relacionada às diferenças no alimento, mas também a vários outros fatores, tais como os comportamentais. Machos necessitam sair em busca de fêmeas para a cópula. Desta forma, emergindo antes os machos podem garantir a cópula com as fêmeas que emergirem próximo ao local onde o macho se encontra. Como C. phyllinus possui pouca mobilidade, apesar do macho voar e ser mais ativo na corte de acasalamento (Dorval et al. 2003), provavelmente esta seja uma estratégia para incrementar o potencial biótico, não só desta espécie, mas da maioria dos fasmídeos.

A duração do período ninfal dos machos do bicho-pau foi menor do que o das fêmeas, tanto para aquelas com oito instares como para aquelas com nove instares (Tabela 1). Os machos levaram aproximadamente 61 dias a menos que as fêmeas para atingirem a fase adulta. As fêmeas com oito instares levaram em média 163,3 dias para atingirem a fase adulta, apresentando uma diferença de 16 dias daquelas com nove instares. Para os machos, o tempo entre uma troca de tegumento e outra (ecdise) foi, em média, de 17 a 22 dias, já para as fêmeas esse tempo foi, em média, de 17 a 28 dias.

Quando alimentados com folhas de angico (Piptadenia spp.), os machos de B. tuberculata (C. phyllinus) passaram por seis e sete instares, com duração ninfal de 126,0 e 142,2 dias, respectivamente (Dorval et al. 2003). Para as fêmeas com oito e nove instares as durações foram de 169,4 e 203,8, respectivamente.

A viabilidade do período ninfal do bicho-pau foi de 68\% (Tabela 2), diferindo do observado por Dorval et al. (2003) que foi de $57,1 \%$, quando as ninfas desta espécie foram alimentadas com folhas de angico.

Das 34 ninfas de C. phyllinus que atingiram a fase adulta, 19 delas resultaram em machos e 15 em fêmeas, com uma razão sexual de aproximadamente 1:1 (Tabela 2). Resultado semelhante foi obtido por Dorval et al. (2003), onde 11 fêmeas completaram o período ninfal com oito instares e quatro com nove instares e 13 machos completaram com cinco instares e seis com seis instares.
Tabela 2. Duração da fase ninfal e longevidade de adultos (dias) de Cladomorphus phyllinus alimentados com folhas de goiabeira. Temperatura de $27 \pm 1^{\circ} \mathrm{C}$; UR de $50 \pm 10 \%$; fotofase de 12 horas.

\begin{tabular}{ccccc}
\hline Fase & Sexo & $\begin{array}{c}\text { Duração } \\
\text { (dias) }\end{array}$ & Amplitude & $\begin{array}{c}\text { Indivíduos } \\
\left(\mathbf{n}^{\mathbf{0}}\right)\end{array}$ \\
\hline Ninfal & $\hat{O}_{(1)}$ & $102,6 \pm 8,6$ & $91-117$ & 13 \\
& $\hat{O}_{(2)}$ & $117,7 \pm 8,7$ & $108-133$ & 6 \\
& $\overbrace{(3)}$ & $163,3 \pm 21,5$ & $129-195$ & 11 \\
\hline \multirow{2}{*}{ Adulta } & $\overbrace{(4)}$ & $179,3 \pm 16,3$ & $156-196$ & 4 \\
& $\overbrace{}^{\Uparrow}$ & $208,6 \pm 37,3$ & $151-267$ & 9 \\
\hline
\end{tabular}

${ }^{1}$ ninfa com 5 ínstares; ${ }^{2}$ ninfa com 6 ínstares; ${ }^{3 n i n f a}$ com 8 ínstares; ${ }^{4}$ ninfa com 9 ínstares

As fêmeas de C. phyllinus alimentadas com folhas de goiabeira viveram em média 80,9 dias a mais do que os machos (Tabela 2). Os machos desta mesma espécie quando alimentados com folhas de angico também viveram menos que as fêmeas, entretanto, as fêmeas alimentadas com angico foram menos longevas (159,3 dias), vivendo somente 36,65 dias a mais que os machos (DORVAL et al. 2003). ZAPATA \& TORRES (1970) observaram que enquanto os machos de $B$. granullicolis viveram poucos dias, as fêmeas viveram de sete a nove meses.

O período de oviposição iniciou-se em média 29,4 dias após a emergência das fêmeas de $C$. phyllinus e transcorreu durante 164,4 dias (Tabela 3). Esses resultados são muito próximos aos observados por Dorval et al. (2003) quando os insetos se alimentaram de folhas de angico.

As fêmeas de C. phyllinus realizaram 224,o posturas, colocando em média 392,3 ovos, e demonstraram não possuir preferência por ovipositar na presença de luz ou no escuro (Figura 1). $\mathrm{Na}$ presença de luz, ou seja, quando as coletas de ovos foram realizadas no final da tarde, foram obtidos, em média, 208,11 ovos, resultantes de 105,6 posturas. Quando as coletas dos ovos

Tabela 3. Período de pré-oviposição (dias) e de oviposição (dias), número de posturas, número de ovos, período médio de incubação (dias) e número de ninfas eclodidas de Cladomorphus phyllinus alimentados com folhas de goiabeira.

\begin{tabular}{|c|c|c|c|c|c|c|}
\hline Casal & $\begin{array}{c}\text { Pré-oviposição } \\
\text { (dias) }\end{array}$ & $\begin{array}{c}\text { Oviposição } \\
\text { (dias) }\end{array}$ & No $^{\circ}$ posturas (n) & No Ovos (n) & $\begin{array}{c}\text { Incubação } \\
\text { (dias) }\end{array}$ & $\begin{array}{c}\text { Número de } \\
\text { ninfas eclodidas }\end{array}$ \\
\hline 1 & 19 & 245 & 361 & 670 & 150,9 & 203 \\
\hline 2 & 24 & 185 & 293 & 594 & 160,7 & 130 \\
\hline 3 & 48 & 92 & 56 & 62 & - & o \\
\hline 4 & 37 & 131 & 157 & 229 & - & o \\
\hline 5 & 23 & 183 & 294 & 502 & 154,8 & 119 \\
\hline 6 & 29 & 235 & 341 & 609 & 156,2 & 151 \\
\hline 7 & 29 & 191 & 259 & 470 & 174,5 & 101 \\
\hline 8 & 30 & 71 & 74 & 109 & 142,0 & 24 \\
\hline 9 & 26 & 147 & 181 & 286 & 100,0 & 58 \\
\hline Média & $29,4 \pm 2,9$ & $164,4 \pm 19,8$ & $224,0 \pm 37,3$ & $392,3 \pm 75,5$ & $148,4 \pm 8,9$ & $87,3 \pm 23,7$ \\
\hline
\end{tabular}

foram realizadas na parte da manhã, ou seja, foram ovipositados durante a noite, 184,2 ovos foram obtidos em média, resultantes de 118,4 posturas. Foi constatado que na presença de luz as fêmeas realizaram menos posturas, mas colocaram maior número de ovos, aproximadamente 2 ovos a mais por postura. DoRval et al (2003) obtiveram resultados distintos para esta espécie quando alimentada com folhas de angico, pois na presença de luz constataram que as fêmeas também realizaram menos posturas
(44,7 posturas), porém colocaram menos ovos (75,0 ovos/fêmea), e no escuro, além de mais posturas (121,2 posturas), colocaram 294,3 ovos/fêmea. Estes autores observaram que, somando as posturas realizadas pelas fêmeas no período de luz e aquelas realizadas no escuro, quando foram alimentadas com folhas de angico, o total de ovos por fêmea foi, em média, de 369,3. Esses resultados foram muito próximos ao encontrado no presente estudo (392,3 ovos/fêmea), quando os insetos se alimentaram 
de folhas de goiabeira. ZAPATA \& TORRES (1970) constataram para outra espécie de bicho pau, B. granullicolis, uma média de 500 ovos por fêmea. Para $H$. mexicana, uma espécie muito próxima de B. granullicolis, CAmousseight (2003) encontrou 480 ovos por fêmea em média, mas com viabilidade de apenas $31,4 \%$. Das ninfas eclodidas somente $1,7 \%$ passaram do primeiro instar ninfal e destas $1,3 \%$ atingiram a fase adulta.

O período de incubação dos ovos de $C$. phyllinus foi, em média, de 148,4 dias, bem acima ao observado por Dorval et al. (2003), que foi de 107,4 dias (Tabela 3). Segundo Lima (1938), $P$. phyllinum (C. phyllinus) alimentado com folhas de Ficus coloca em média 152 ovos e as larvas eclodem 113 dias após a postura, demonstrando o quão lento é o desenvolvimento embrionário deste inseto. BEDFORD (1978) constatou que algumas espécies de Cladomorphus apresentaram períodos de incubação que variaram de 60 a 80 dias, quando os ovos foram fertilizados e de 85 a 110 dias, quando não fertilizados. Essa diferença no período de incubação, segundo o autor, pode chegar a até 280 dias, apesar da maioria dos ovos terem apresentado período de incubação variando de 85 a 110 dias. Do total de ovos colocados por fêmea de $C$. phyllinus eclodiram, em média, 87,3 ninfas, ou seja, uma viabilidade média dos ovos de 22,3\% (Tabela 3). Algumas espécies podem apresentar uma viabilidade de ovos maior, como a observada por CAmousseight (2003) em $H$. mexicana, 31,4\% em média. No entanto, o autor verificou que das ninfas eclodidas somente $1,7 \%$ passa do primeiro instar e destes, somente $1,3 \%$ alcança a fase adulta.

Embora a espécie $C$. phyllinus, quando alimentada com folhas de goiabeira, tenha se mostrado fecunda, a baixa viabilidade dos ovos aliado ao longo período de incubação e ninfal pode justificar a baixa população dessa espécie em áreas cultivadas, não provocando danos, já que é uma espécie com baixo potencial reprodutivo.

As informações obtidas nesta pesquisa irão incrementar as publicações relacionadas a ordem Phasmatodea no Brasil e podem encorajar mais estudos sobre a biologia de outras espécies deste grupo, tão pouco conhecido no país.

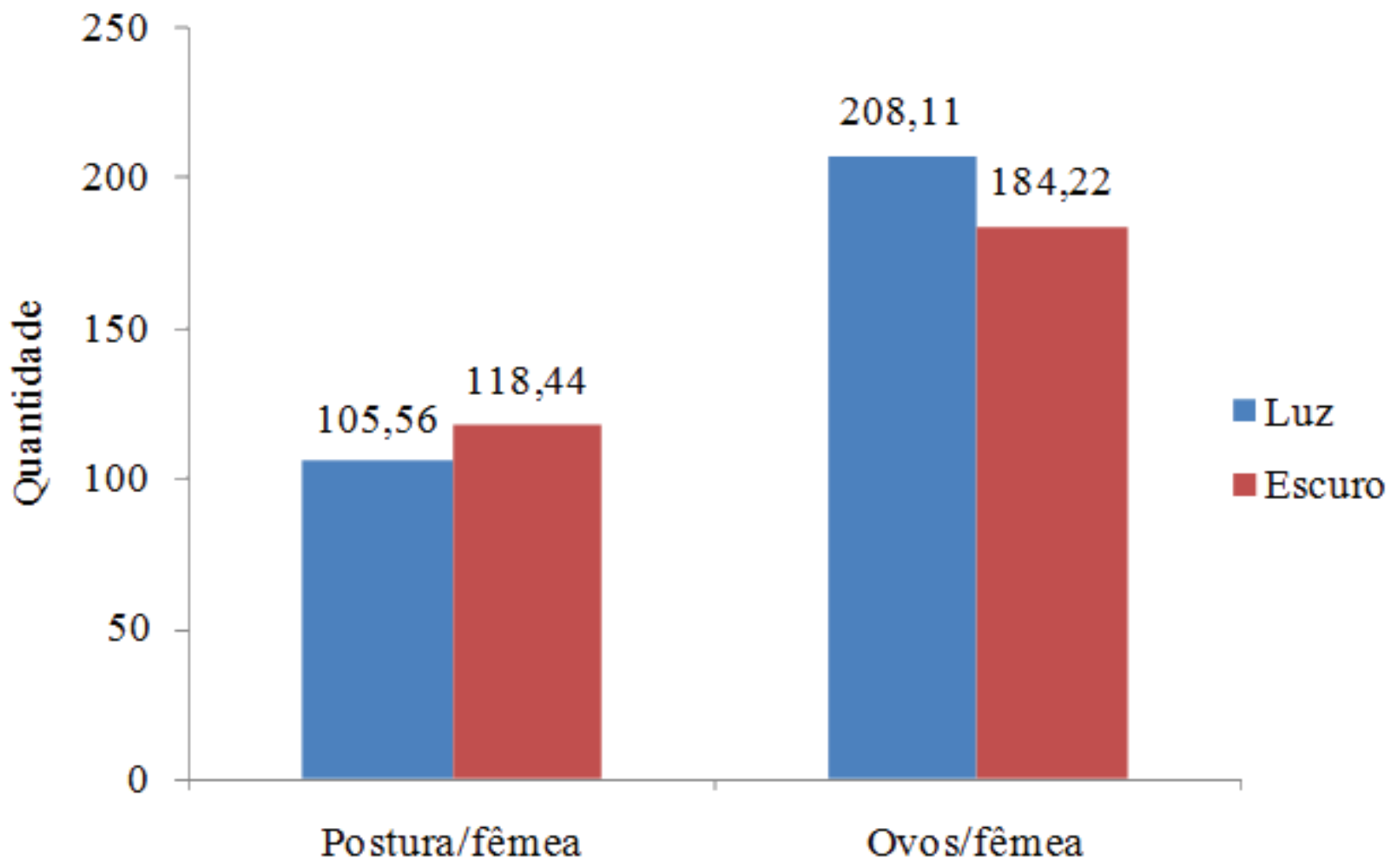

Figura 1. Número de ovos e de posturas por fêmea de Cladomorphus phyllinus obtidos em período de luz ou de escuro quando alimentadas com folhas de goiabeira.

\section{AGRADECIMENTOS}

Os autores agradecem a FAPEMIG (Fundação de Amparo à Pesquisa do Estado de Minas Gerais) e ao CNPq (Conselho Nacional de Desenvolvimento Científico e Tecnológico) pelas bolsas concedidas aos autores.

\section{REFERÊNCIAS}

Aliaga, M.M., 2015. Orden Phasmatodea. Revista IDE@ - SEA, 45: 1-11. Disponível em: <http://sea-entomologia.org/IDE@/ revista 45.pdf $>$. [Acesso em: 12.xii.2017].

Baker, E.W., 2015. The worldwide status of phasmids (Insecta: Phasmida) as pests of agriculture and forestry, with a generalized theory of phasmid outbreaks. Agriculture \& Food Security, 4:1-19. DOI: https://doi.org/10.1186/s40066-0150040-6.

Bedford, G.O., 1978. Biology and ecology of the Phasmatodea. Annual Review of Entomology, 23: 125-149. DOI: https://doi.org/10.1146/annurev.en.23.010178.001013.
Bisby, F.A., Y.R. Roskov, T.M. Orrell, D. Nicolson, L.E. Paglinawan, N. Bailly, P.M. Kirk, T. Bourgoin \& J.Van Hertum, 2008. Species 2000 \& ITIS Catalogue of Life: 2008 Annual Checklist Taxonomic Classification. Species 2000: Reading, U.K. Disponível em: <http://www.catalogueoflife.org/ annual-checklist/2008/show species details.php?record $\underline{\mathrm{id}=4621481}>$. [Acesso em: 12.xii.2017].

Brock, P.D., Büscher, T. \& Baker, E. 2018. Phasmida Species File Online. Version 5.0/5.0. Disponível em: <http://phasmida. speciesfile.org>. [Acesso em: 25.1.2018].

Buzzi, Z.J. \& R.D. Miyazaki, 1993. Entomologia didática. Curitiba: UFPR, $262 \mathrm{p}$.

Buzzi, Z.J., 1994. Coletânea de nomes populares de insetos do Brasil. Curitiba: J.Z. Buzzi, 230 p.

Camousseight, A., 2003. Biología de Heteronemia mexicana Gray, 1835 (Phasmatodea, Diapheromeridae), una especie con reproducción explosiva, asociada a bosque de pino. Boletín del Museo Nacional de Historia Natural, 52: 7-15. 
Disponível em: <http://publicaciones.mnhn.cl/668/articles64485 archivo 01.pdf>. [Acesso em: 16.i.2018].

Campbell, K.G., 1966. A new technique of aerial spraying for control of phasmatids. Journal of the Entomological Society of Australian, 3: 36-38. Disponível em: <https://search. informit.com.au/documentSummary; $\mathrm{dn}=229655501173046$ ;res=IELHSS $>$ [Acesso em: 26.x.2017].

Chiquetto-Machado, P.I.\& F.F. Albertoni, 2017. Description of the female,eggandfirstinstarnymphofthestickinsectParaphasma paulense (Phasmatodea: Pseudophasmatidae) from Southeast Brazil. Journal of Orthoptera Research, 26: 91-101. DOI: https://doi.org/10.3897/jor.26.20180.

Costa Lima, A.M., 1938. Insetos do Brasil. $1^{\circ}$ tomo. Escola Nacional de Agronomia, Rio de Janeiro. Série didática. $468 \mathrm{p}$.

Dorval, A., O. Peres-Filho, C. S. P. Moraes \& E. Berti-Filho, 2003. Biologia e estudo comportamental de Bacteria tuberculata Piza Jr., 1939 (Phasmatodea; Phasmatidae) em folhas de anjico (Piptenia spp.). Scientia Forestalis, 63: 150-157. Disponível em: <http://www.ipef.br/publicacoes/scientia/ nr63/cap12.pdf > [Acesso em: 20.iv.2017].

Heleodoro, R.A., D.M.M. Mendes \& J.A. Rafael, 2017. Studies on Brazilian Pseudophasmatidae (Phasmatodea) with the description of a new species of Agrostia Redtenbacher and new records for Metriophasma Uvarov and Parastratocles Redtenbacher. Revista Brasileira de Entomologia, 61: 170177. DOI: https://doi.org/10.1016/j.rbe.2017.03.003.

Hennemann, F.H., O.V. Conle \& D.E. Perez-Gelabert, 2016. Studies on Neotropical Phasmatodea XVI: Revision of Haplopodini Günther, 1953 (rev. stat.), with notes on the subfamily Cladomorphinae Bradley and Galil, 1977 and the descriptions of a new tribe, four new genera and nine new species (Phasmatodea: "Anareolatae": Phasmatidae: Cladomorphinae). Zootaxa, 4128: 1-211. DOI: https://doi.org/10.15468/voawld.
Kumagai, A.F. \& N.G. Fonseca. 2009. Uma nova espécie de Cladomorphus Gray, 1835 (Phasmatidae, Cladomorphinae) de Minas Gerais. Revista Brasileira de Entomologia, 53: 41-44. DOI: https://doi.org/10.1590/s0085-56262009000100011.

Lenko, K. \& N. Papavero, 1996. Insetos no Folclore. São Paulo, Plêiade/FAPESP, $468 \mathrm{p}$.

Santos, E., 1982. Os insetos. Belo Horizonte, Itatiaia, 203 p.

Sottoriva, L.D.M., L. Picolo, L.C.H. Ramos \& A.R. Roel, 2008. Preferência alimentar e biologia reprodutiva do bichopau Phibalosoma phyllinum Gray, 1835 (Phamatodea, Phasmatidae) em criações de laboratório. Multitemas (UCDB), 35: 135-148.

Toledo Piza, S., 1944. Cinco novas espécies de Phásmidas do Brasil. Anais da Escola Superior de Agricultura "Luiz de Queiroz", 1: 43-58. DOI: https://doi.org/10.1590/Soo7112761944000100004 .

Triplehorn, C.A. \& N.F. Johnson, 2005. Borror and Delong's introduction to the study of insects. $7^{\text {th }}$ ed. Thomson Brooks/ Cole. 864 p.

Whiting, M.F., S. Bradler \& T. Maxwell, 2003. Loss and recovery of wings in stick insects. Nature, 421: 264-267. DOI: https://www.nature.com/articles/nature01313.

Zapata, S. \& E. Torres, 1970. Biologia y morfologia de Bacteria granullicolis (Blanchard) (Phasmida). Publicaciones del Centro de Estudios Entomológicos del Chile, 10: 23-42.

Zompro, O. \& F.C. Domenico, 2005. Catalogue of the type material of Phasmatodea (Insecta) deposited in Brazilian Museums. Iheringia, Serie Zoologia, 95: 255-259. DOI: http://dx.doi.org/10.1590/So073-47212005000300005.

$* * * * * * * * * *$

\section{Suggestion citation:}

Alvarenga, C.D., H.R. Souza, T.A. Giustolin, C.A.R. Matrangolo \& J.F. Silva, 2018. Biologia de Cladomorphus phyllinus Gray (Phasmatodea: Phasmatidae) em folhas de goiabeira (Psidium guajava). EntomoBrasilis, 11 (2): 65-69.

Available on: doi:10.12741/ebrasilis.v11i2.762
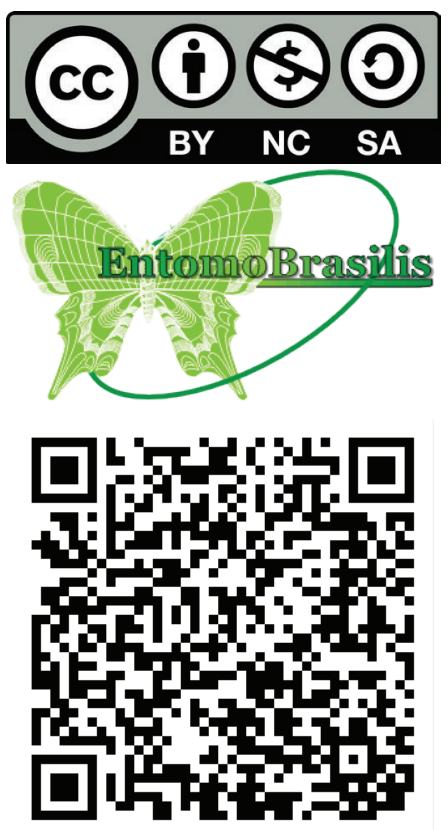